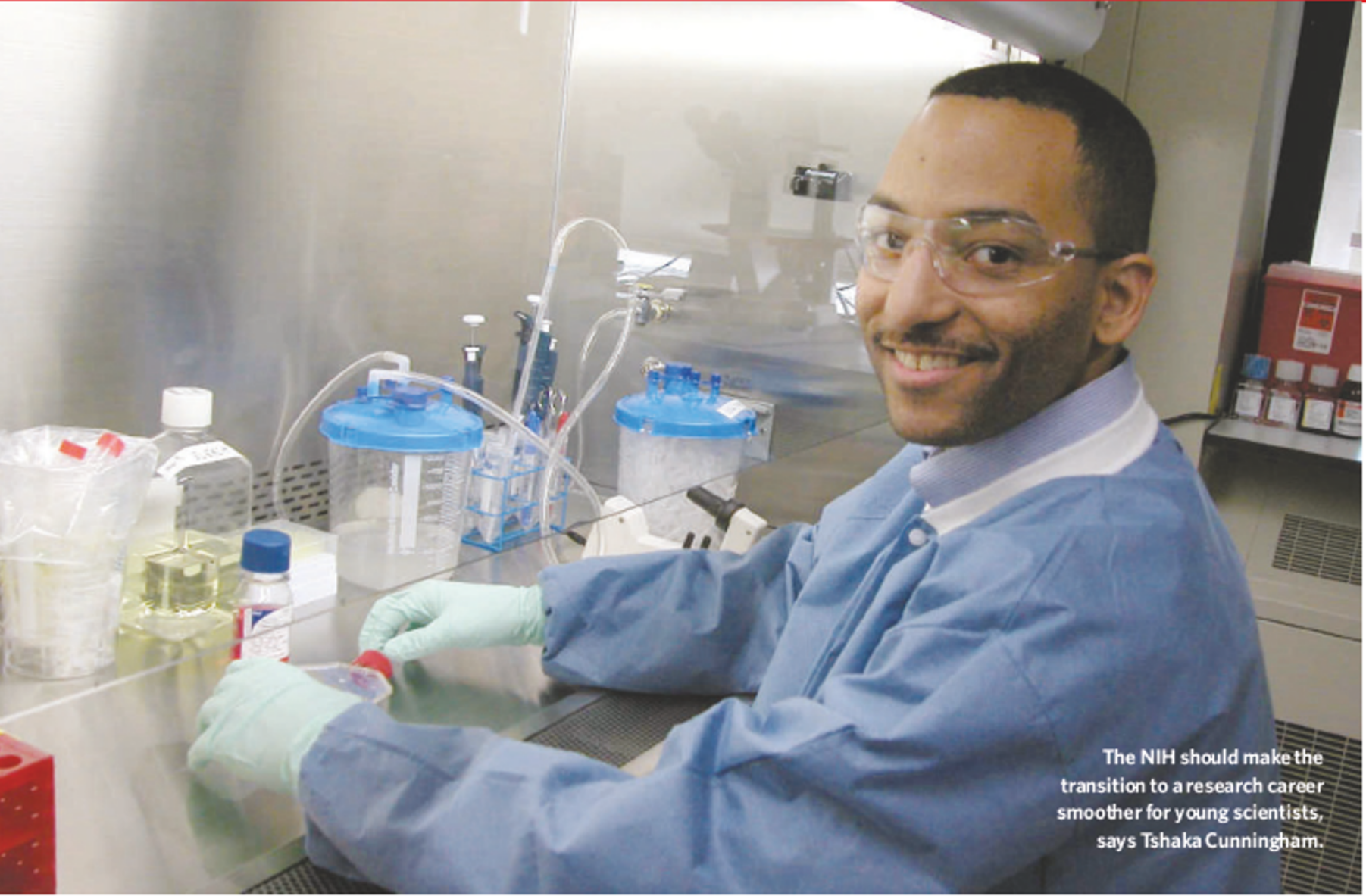

\title{
IT'S A POSTDOC'S LIFE
}

\section{Does the respected US National Institutes of Health meet the needs of young postdoc researchers? Jacqueline Ruttimann investigates.}

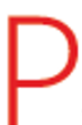

lace yourself, for a moment, in the lab coat of a US postdoctoral fellow. You've just spent four to seven years working on your graduate-school dissertation, but the journey is not yet complete. At a time when many of your friends are making good money at real jobs, you have to work in another laboratory for almost the same time it took to complete grad school. Fail to receive funding and publish frequently, and your dream of one day heading your own lab will go up in smoke.

The odds are stacked against you - and the roughly 45,000 other postdocs in the country. The most recent data from the National Science Foundation show that, of those who were postdocs in 2001, less than one-quarter had moved into a tenure-track university position two years later.

Nevertheless, more than 20,000 postdocs work each year under the auspices of the US National Institutes of Health (NIH), the largest funding source for postdoc research in the country. Just over $10 \%$ of these young scientists work on 'intramural" research at the agency's main campus in Bethesda, Maryland. The rest rely on NIH funding for extramural research in labs across the country.
In many ways, the NIH is an ideal place to be a postdoc. Although its budget is being cut back now, the agency had been relatively flush with cash in recent years, and its director Elias Zerhouni has made young investigators a priority during his tenure (see page 17). Yet even at the $\mathrm{NIH}$, postdocs struggle to acquire the skills needed to develop their own line of research and score a coveted tenure-track position. Nature spoke with four postdocs who are at key points along the journey to becoming a fledgling scientist.

\section{Academia to industry}

Sometimes the hardest thing about doing a postdoc is making the decision to become one. According to a survey by the research society Sigma $\mathrm{Xi}$, the typical US postdoc makes an average salary of just $\$ 38,000$. Financial concerns can often draw young scientists off into industry or other more lucrative careers. ${ }^{\alpha}$ Those of us who decide to stick with academic science have to make a financial sacrifice that we shouldn't be making," says Tshaka Cunningham, who started a postdoc four months ago at the National Cancer Institute's vaccine branch on a project to develop an AIDS vaccine.
Even so, Cunningham is infused with the energy of a young scientist. He has lots of ideas - so many that he keeps a notebook by his bed, thinking that he might one day use some of them at a university tenure-track position or as a consultant in the biotechnology industry. For now, he hopes that the NIH can help to steer him down either path.

It's a big request for an agency reeling from a conflict-of-interest scandal, in which NIH investigators were chastized for regularly accepting large consulting fees from pharmaceutical companies and others whose products

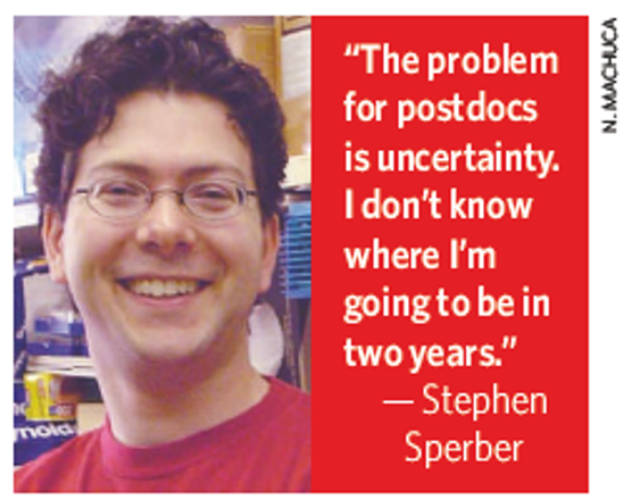




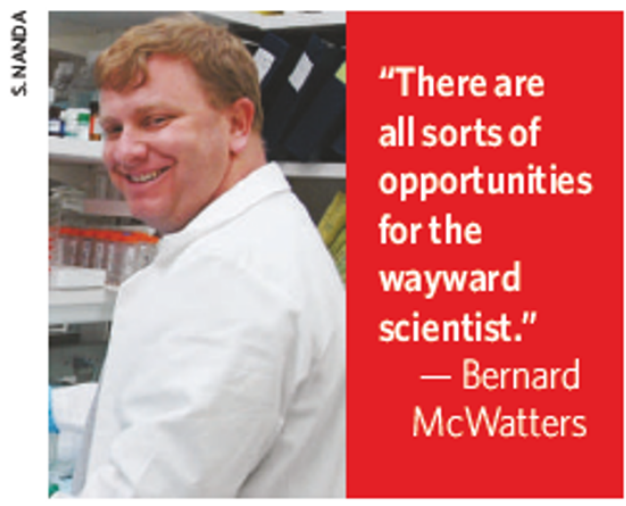

they evaluated. Cunningham is experiencing some of the backlash from this scandal, as everything down to his involvement with a non-profit organization he helped to found before his arrival, the National Association for Blacks in Bio, is being carefully scrutinized under new, more stringent $\mathrm{NIH}$ ethics rules.

Still, he'd like to see the NIH adopt a more seamless relationship with industry so that postdocs could apply for industry grants while finishing their mentor's research project. As a graduate student at the Rockefeller Institute in New York, Cunningham combined his main project with a scheme funded by a $\$ 40,000$ grant, part of which came from Merck, the New Jersey-based pharmaceutical giant. ${ }^{\text {कT The }}$ $\mathrm{NIH}$ should be an intermediary between academia and industry," he says.

That's unlikely to happen any time soon, but the NIH is focusing on smoothing relationships between academic disciplines. The agency is moving towards integrating training programmes for different disciplines, so that postdocs can more readily move between dif-

₹ ferent laboratories at the various institutes,

\& says Michael Gottesman, the NIH's deputy director for intramural research. For now, that means having bench-bound postdocs attend a weekly course called Demystifying Medicine, among others, in which they learn more about the medical research that might spring from their lab findings.

\section{Can postdocs manage?}

Career training is what many postdocs crave most, according to the recent Sigma Xi survey. Many feel they have plenty of experience and training in the laboratory, but want more structured approaches to bigger career questions. Stephen Sperber, a second-year postdoc in a molecular biology lab at the National Institute of Child Health and Human Development, says that although he enjoys his work, the future is a bit worrisome. "As comfortable as I am now, this is not a job, ${ }^{n}$ he says. ${ }^{\circ}$ That's the problem for postdocs: a lot of uncertainty. I don't know where I'm going to be in two years."

Like most, he would like to run his own laboratory one day. But that will take some luck. Regardless of where they train, the average age at which a postdoc gets awarded his or her first independent research grant has been creeping up over time - from age 37 in 1980, to 42 in
2002. Only $6 \%$ of the much-desired 'R01' research grants go to new investigators.

${ }^{\star}$ That transition from postdoc to primary investigator is a very difficult one, admits Gottesman. One way the NIH is trying to help is through the new Pathway to Independence award, in which researchers in the middle of their postdocs can apply for a bridge award of up to $\$ 1$ million - to fund the rest of their postdoc years and the beginning of their independent research. The award, says Gottesman, is "a morale builder".

Postdocs generally agree, but say launching a career in science takes more than just money. Many young postdocs often complain that they need management skills, training which usually takes a lower priority than getting a particular experiment done or a research paper written up. For them, the NIH has set up a course called Making the Right Moves: A Practical Guide to Scientific Management for Postdocs and New Faculty, says Norka Ruiz Bravo, deputy director for extramural research. The problem is, many postdocs are often not aware of such training opportunities, because they are too isolated in their particular institute or simply have not been able to find the information they need.

\section{Alternative paths}

There are also those who decide that bench life is not for them. Bernard McWatters has just finished a postdoc on a project linking polio vaccines to cancer. An affable young man with twinkling eyes and a mouth usually curled up in a smile, McWatters was extremely focused when it came to looking for a job. He knew he

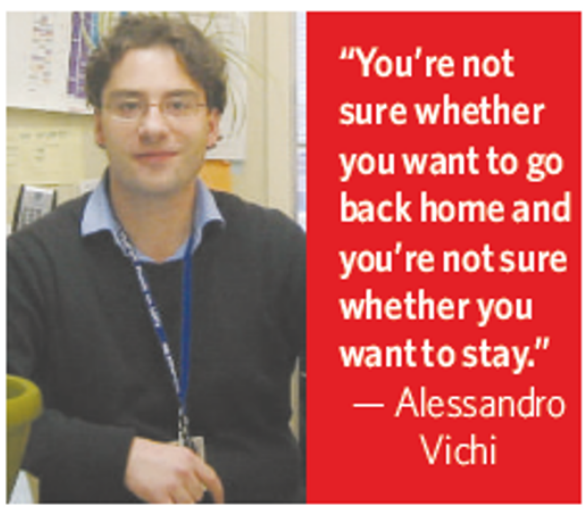

wanted to work at the US Food and Drug Administration (FDA) and achieved it by doing a hybrid postdoc between the FDA and the NIH, in which he spent half of his time at the bench and the other half doing regulatory work. He will soon start a regulatory-affairs job at the FDA's Centers for Biological Evaluation and Research. ${ }^{\alpha}$ There are all sorts of opportunities for the wayward scientist looking for a job, ${ }^{\text {D he says. }}$

McWatters ought to know. He has served as chairman of a career development subcommittee of a larger group set up to improve communication between postdocs and the $\mathrm{NIH}$ community. McWatters helped to sponsor

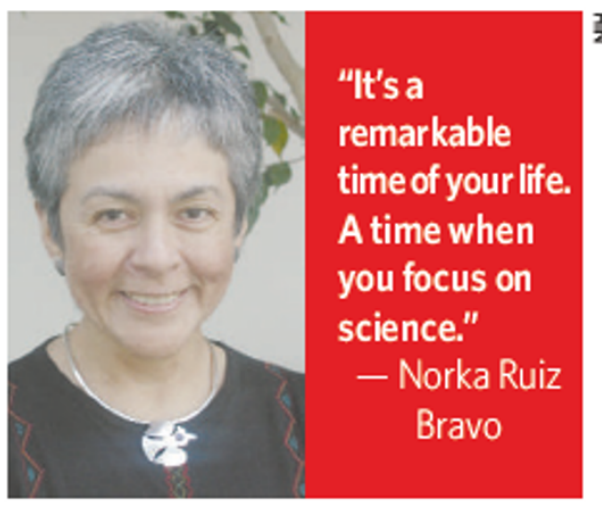

monthly seminars on alternative careers, including such fields as patent law, science policy, medical communication and science consulting. He advises postdocs not to focus on just one career path, and not to wait until the end of their postdoc to start looking for jobs.

The job hunt brings other complications for international postdocs. More than two-thirds of the NIH's intramural postdocs arrive from other countries, often on a visa that ties them to a particular mentor's lab. Alessandro Vichi, who came from Italy to work as a postdoc for five years at the NIH, says that the academic pressures are similar for US and international postdocs. But those visiting from abroad have to worry about visa issues, particularly since regulations were tightened after the terrorist attacks of 11 September 2001. "You're waiting without making a plan," says Vichi, who is now a research fellow at the National Heart, Lung, and Blood Institute. ${ }^{\alpha}$ You're not sure whether you want to go back home and you're not sure whether you want to stay."

Regardless of whether foreigners decide to stay or leave the country after their postdoc, Gottesman argues that all receive sufficient training to get jobs. Those who stay, he says, are often successful in finding work - even if they are in the biotech industry or government rather than an elusive tenure-track position. “Unemployment among people with postdoc experience is very low," he says.

But even NIH officials admit that there is little evidence to support this reported success. The NIH has no formalized tracking system to follow where postdocs end up, which makes it difficult to monitor the success of their training. Bravo says that a tracking system is in the works, but is proving difficult to design as each of the agency's 27 separate institutes and centres have postdocs supported on different types of fellowships.

Despite all the trials and tribulations that come with being a postdoc, it is often considered one of the most productive periods of a scientist's career. "It's a remarkable time of your life when you're unencumbered with the responsibilities that go with becoming an independent investigator," says Bravo, who fondly remembers her days as a postdoc. 'It's a time when you focus on science." Jacqueline Ruttimann is an internin Nature's Washington office. 